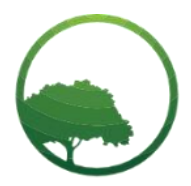

Research in Business \& Social Science

IJRBS VOL 10 NO 4 ISSN: 2147-4478

Business \& Social Science

IJRBS

\title{
Uncovering trust signals in equity crowdfunding: A systematic literature review
}

Semen Son-Turan

Associate Professor, Department of Business Administration, MEF University, Ayazaga Cad. No. 4, Maslak, 34396, Istanbul, Turkey

\begin{tabular}{l} 
A R T I C L E I N F O \\
\hline Article history: \\
Received 12 May 2021 \\
Received in rev. form 27 May 2021 \\
Accepted 29 May 2021 \\
Keywords: \\
Equity crowdfunding, sustainability, \\
blockchain, financing, systematic \\
literature review \\
JEL Classification: \\
M10, M13, M19
\end{tabular}

\begin{abstract}
A B S T R A C T
The purpose of this exploratory study has been to provide insight into the success factors of ECF campaigns and, in particular, explore the role of trust. In specific, the research questions for this study are: (1) What dimensions of ECF success have been studied so far, and (2) is there any established literature on sustainability, blockchain technology and trust in the realm of ECF. To that end, a systematic literature review is conducted by investigating ISI Web of Science and Scopus, two major academic databases, through relevant keyword combinations. The theoretical framework relies on signaling, legitimacy and stakeholder theories. Findings indicate that the role of trust is an emerging theme, and sustainability and BT in relation to trust, to the best of the author's knowledge, is not yet focused upon in crowdfunding research. This study contributes to the literature of crowdfunding and entrepreneurship.
\end{abstract}

(C) 2021 by the authors. Licensee SSBFNET, Istanbul, Turkey. This article is an open access article distributed under the terms and conditions of the Creative Commons Attribution (CC BY) license (http://creativecommons.org/licenses/by/4.0/).

\section{Introduction}

The bloom of Internet banking in the 1990s laid the foundation of today's "modern" financial services industry with concurrent regulatory gaps either paving the way to the misuse of innovation (Son-Turan, 2017) or causing liquidity constraints that opened up the stage for disruptive competitors, such as new generation financial intermediaries, like crowdfunding platforms. Unsettling to traditional financial services providers on the hand; due to its low barriers of entry a medium for the democratization of finance; crowdfunding, on the other hand, in the digital context, is a relatively new concept with its origins dating back to ArtistShare in 2003, a website where musicians could seek donations from their fans to produce digital recordings (Freedman and Nutting, 2015).

The logic of crowdfunding is quite simple: An online platform acting as facilitator that brings together projects/ventures that seek financing and parties who contribute their funds to obtain either no returns (donations-based), mostly non-monetary rewards like the product itself (rewards-based), or financial returns in the form of a quoted interest (debt or lending-based), or an equity stake in the venture (equity crowdfunding, "ECF”).

Trust is an essential element in all kinds of cooperation and, even more so, in the uncertain and mostly unverifiable world of ECF. The concept of trust is difficult to narrow down, mainly because it is rather subjective and dynamic, since it is affected by many factors that are hard to monitor (Yan and Cofta, 2004).

Trust has been defined as one party's belief that its needs will be fulfilled in the future by actions undertaken by the other party (Anderson and Weitz, 1989), and exists when one party has confidence in an exchange partner's reliability and integrity (Morgan and Hunt, 1994), enabling it to tolerate uncertainty through the expectation that the other party will seek to reduce their vulnerability to unpredicted contingencies (Solomon and Flores, 2003).

The research questions for this study are: (1) What dimensions of ECF success have been studied so far?, and (2) is there any established literature on blockchain technology and ECF.

* Corresponding author. ORCID ID: 0000-0002-7457-8417

(C) 2021 by the authors. Hosting by SSBFNET. Peer review under responsibility of Center for Strategic Studies in Business and Finance.

https://doi.org/10.20525/ijrbs.v10i4.1187 
This exploratory study sets out to contribute to the limited literature on ECF success by providing a discussion surrounding important issues in relation to ECF (section 2), and conducting a systematic literature review to determine the success factors of ECF campaigns and the role of trust established in previous studies that are published in the Web of Science (WoS) and Scopus databases (section 3). Subsequently, the theoretical framework that is centered on legitimacy, stakeholder, and signaling theories (section 4), is presented. A discussion of potential "trust signals" is provided in section 5 followed by the conclusion in section 6 .

\section{Background}

\section{The ECF environment and the question of success}

Similar to venture capital financing, ECF, in contrast to the other types of crowdfunding, might be considered to be less attractive for ventures, due to more complicated contracts, elongated due diligence processes, and respective costs, as well as stringent filing and compliance requirements by regulatory institutions depending on the country's legislation. From the perspective of the platform, ECF is relatively more demanding infrastructure-wise and highly dependent upon a favorable legal framework being in place. Furthermore, fierce competition leads entrepreneurs to prefer only the top players. On the investor side, as with traditional equity investments, associated risks require extreme caution and financial literacy.

Due to its low barriers to entry, ECF's fund-seeking clientele is mostly represented by small-businesses and start-ups that do not qualify for bank financing or lack necessary funds to enter rounds of angel or venture capital financing.

According to Statista (s.d.), the transaction value in the crowdfunding segment globally has increased by $+30.3 \%$ YoY and has reached USD 6,839 million, while the number of campaigns has increased by 35.3\% YoY amounting to 8,681 thousand campaigns around the world. The country ranking by transaction value is China (USD 5,572 million), USA (USD 718 million) and the UK (USD 88 million).

While especially the donation- and rewards-based types seem to have enjoyed a good deal of success; it currently is not all roses and butterflies for ECF models, which in the past tended to raise relatively larger amounts of capital (Bellaflamme et al., 2012), and currently constitute the lowest portion (Statista, s.d.).

Another question is how to define success, which is a multi-faceted phenomenon: Is success the achievement of the pledged funds towards the campaign target or the funds collected from the investors that have pledged the funds? The ECF platform Seedrs (Seedrs, s.d.) in the UK for instance, by directly collecting funds from investors, spares itself the trouble of having to "chase" them afterward.

Is success the number of campaigns listed on the platform or the number of campaigns that reach their funding target? From the perspective of the platform, the former may as well be a success factor due to the incoming cash from their listing fees, whereas the latter is definitely a success factor for the entrepreneur seeking funds, and the platform if it charges percentage fees.

Success may also be defined as the improved chance of attaining second-round funding or, for a venture, to live up to its promised performance. Performance, one of the most critical determinants of success, from an investor point of view, is but only one target among many others for the platform which also strives to maintain its reputation and may forego performance to high website traffic and increased visibility.

Unequivocally, the success of ECF, depends on the existence of a promoting and protective legal environment as well as regulations that allow not only the entry of sophisticated but also household, or the so-called "small", "unsophisticated" or "restricted", investors into the crowdfunding eco-system. For instance, in the USA the passage of the JOBS Act in 2012 marks the beginning of the efforts that allow for the entry of the latter.

The success of crowdfunding is also contingent upon its deliverable promises and its ability to "compete" with other similar investment opportunities offered to the same universe of investors. For instance, can an equity crowdfunded campaign compete with the deliverables of a venture capital pitch, or how can it attract investors who are indifferent between dedicating their assets towards debt or equity investments?

Additionally, macro-economic factors play an important role in shaping the availability of disposable funds. Low interest rates in the home country, may lead investors to convert local currency to the currency of higher interest rate countries to invest in that country's higher rated bonds, a situation called "carry trade" in finance. Similarly, high interest rates prevailing in the home country may attract investors to the safety of interest rates offered by banks rather than the vague promises of the ECF market.

Furthermore, success is shaped by conceptual as well as psychological and cultural elements. Investors already invested in crowdfunding campaigns, like debt-based ventures, may be more inclined psychologically to consider ECF investments, a so-called "contagion effect". Moreover, herding and framing effects, namely the visibility of investors who have invested in a certain ECF campaign and the way the campaign is presented by the ECF platform, may influence certain investor groups, especially small investors, to opt for that specific campaign.

The cultural factor can determine what types of campaigns may be successful. In Muslim countries, ECF could, in some sense, be considered sharia-compliant as opposed to interest bearing debt-based crowdfunding. Along the same lines, ECF campaigns must be "halal" (i.e. avoid the offering of forbidden activities like gambling) as prescribed by the sharia. Ethical investment offerings, or what 
we call "socially responsible investments" or "sustainability-related -ESG" activities, may signal trust and attract broader bases of investors.

According to USA-based platform SeedInvest, which leads with an average raise of $\$ 435,780$ per campaign, the fact that they merely launch 1 percent of the startups that apply to raise capital, and invest meaningful time in those startups they select, is the major factor of their success. Similarly, Start Engine, who leads in attracting the most number of campaigns attributes its success to sourcing entrepreneurs with the highest success potential and coaching them throughout the process (Venturebeat, s.d.).

In the UK, Seedrs is named the number one funder of private companies in 2017, who funded 165 deals across the UK and Europe with a market-dominating success rate of $74 \%$, followed by UK Crowdcube. What is said to set Seedrs apart is the fact that they offer a full lifecycle platform, making them a long-term funding partner and not just a transactional platform (Seedrs, s.d.).

Best practice examples undoubtedly exist; however, times are changing swiftly and technology is evolving rapidly along with the growing number of startups looking to get listed on an ECF platform. Therefore, it is vital to understand the context in which these platforms operate.

\section{Issues surrounding ECF that potentially influence trust}

Financing, or buying the debt or equity of any kind of company is inherently risky. Added to this, the more unknowns exist related to the performance of the venture, or the shorter its success story is, the greater the risks for investors.

\section{Risks and Blockchain Technologies as a way to mitigate them}

Son-Turan (2015), identifies the different types of risks potentially encountered at each stage of the ECF process from the perspective of three immediate stakeholders: 1) the entrepreneur seeking funding, 2) the investor, and, 3) the platform, and groups these risks into five categories: financial, regulatory, operational, reputational, and strategic risk. For instance, fraud detection, malpractice and cyber-attacks are operational risks inherent in crowdfunding platforms.

Blockchain technology (BT) is based on asymmetric encryption using a system of keys that allows parties to verify data and identity. The bigger the blockchain, the harder it is for hackers to take down the entire network. At the exit stage, investors are faced mostly with liquidity risks, which limit their options to sell their shares.

Therefore, whether it is risks arising from investor ignorance, or uncertainties of financial, operational, reputational, strategic or regulatory nature, the common denominator is essentially "trust", which can clearly be enhanced through blockchain technology's secure, automated, almost frictionless functioning that enables easy auditing, due diligence and appraisal of the venture.

Inherent risks associated with ECF are oftentimes non-transparent since few opportunities for due diligence and, unlike rounds of angel pitches, mostly no face-to-face contact with the funder and the entrepreneur, exist. Furthermore, the lack of educated managerial planning and adequate financial controls can lead funded ventures to go downhill and never be able to materialize their product.

Cybersecurity risk, fraud and malpractice are among the risks that first come to mind in relation to ECF. 76 percent of platform operators believe there is medium to very high risk of a potential cyber-security breach and 64 percent of platform operators associate fraud to be of medium to very high risk. Also, the collapse of platforms due to malpractice ranks second in terms of risk with 69 platforms considering to prone to very high risk (JBS, s.d.).

Legislation is also an important factor in mitigating risk. Regulatory schemes in countries ranging from the lack of legislation, intermediary platform regulation, banking regulation and two-tiered regulation-crowdfunding platforms, such as those monitored at the US federal level (JBS, s.d.). For instance, countries like the UK, Netherlands, Germany and the USA have more favorable legislation schemes (Infodev, s.d.).

However, legislation takes time, enforcement may be difficult in the virtual landscape and, potential loopholes may be uncovered throughout the process. On the other hand, BT, since it does not rely on a central authority, and functions through a distributed ledger in which all information related to transactions are timestamped and verified by all participants, has the potential to be welcomed by even the most risk-averse investor.

In ECF, one of the main problems is the lack of transparency with respect to the owners of the startup, uncertainties as to their experience and, in most cases, unendorsed credentials, all of which lead to an increase in potential default risk from the perspective of the investor. Through the adoption of a BT platform, like Ethereum, efficiencies in operations, transparency in all transactions, verified and trusted processes, immutable information on the blockchain has the potential to increase trust, reduce existing asymmetric information hinder fraud and produce many more scalable efficiencies.

How popular blockchain technology has already become is exemplified by the European Blockchain Foundation (EBF, s.d.), which alone hosted 175 blockchain-related events in 2018.

Likewise, a multitude of operational advantages exist once the blockchain infrastructure is incorporated. For instance, through Initial Coin Offerings (ICOs) investors can buy crypto-currency tokens that represent shares in the venture (i.e. crypto-equity). By way of smart contracts, enabled by blockchain technology, funds can be released when targets are met. Simultaneously, greater oversight of 
campaigns will increase trust and uncertainties in ECF. Furthermore, platform transaction costs can potentially be lowered significantly.

The global blockchain market size is expected to grow from USD 1.2 billion in 2018 to USD 23.3 billion by 2023, at a compound annual growth rate (CAGR) of $80.2 \%$ which is attributed to factors such as increasing venture capital funding and investments in blockchain technology, a growing need to simplify business processes and create business transparency and immutability, reduction in operational cost, and increasing popularity of blockchain in retail and supply chain management (PRNewswire, s.d.). This growth will sure create a ripple effect for smaller industries, like the crowdfunding industry, as well.

While ECF was initially viewed as a platform for the democratization of finance, it turned out to be too restricting with excessive platform fees, lots of uncertainties and low success rates. New startups that have recognized the pitfalls of ECF, are applying decentralized ledger technology to crowdfunding activities. A token system, called OAK, has been created that allows users on both sides of the platform to crowdfund free of fees. This way fees reaching $10 \%$ for fundraisers have been effectively eliminated, making the platform much more user friendly. Additionally, the BT platform allows any legal and non-harmful project from anywhere on the globe to easily fundraise, something that no other crowdfunding platform allows for (Acorn, s.d.).

\section{Sustainability as a proactive way to entice impact investors}

Crowdfunding is not only a venue to raise capital but can also promote awareness, create jobs, stimulate innovation, and advance entrepreneurship.

As such, a group of UN employees has founded the UN Blockchain (s.d.) "Multi-UN Agency Platform" under the motto "Imagine; that every single person on earth will have an ID and get access to education, health and other social services; that 2.5 billion unbanked people will be included in the global financial system, [...]" (Multi-UN, s.d.). The interest of the UN in blockchain technology could be triggered by its search for the resilience of UN services in order to survive even the destruction of the UN itself (Medium, s.d.).

Registered with the UN Department of Economic and Social Affairs, The World Blockchain Organization (WBO) encourages the implementation of the Global Code of Ethics for blockchain community, to maximize blockchain technology's socio-economic contribution while minimizing its possible negative impacts, and is committed to promoting blockchain technology as an instrument in achieving the United Nations (UN) Sustainable Development Goals (SDGs), geared towards fostering sustainable development worldwide (UNWBO, s.d.).

Another trust-boosting "signal" is the implementation of sustainability-related principles into operations and the culture of the venture. Impact measurement is made possible through sustainability reporting practice by way of adoption of the standards developed by the Global Reporting Initiative (GRI, s.d.) or an integrated framework such as that offered by the International Integrated Reporting Council (IIRC, s.d.), which aims at showing the connectivity of strategic objectives, risk and performance to demonstrate how organizations create value, essentially involving financial as well non-financial elements of the venture.

According to the UNDP, the incorporation of sound social and environmental standards and accountabilities within the business operations of crowdfunding platforms will encourage transparency, accountability, and rigorous reporting to reduce green washing, fraud and malpractice (UNDP, s.d.).

On January 29, 2018 the OECD held a conference in Paris on "Private Finance for Sustainable Development" whose focus was the crucial role private finance plays in achieving the goals set in the UN Sustainable Development Goals (SDGs) and the Paris Agreement ${ }^{1}$.

Crowdfunding by nature, serves towards: SDGs 1 (no poverty), 2 (zero hunger), 8 (decent work and economic growth), and 10 (reduced inequalities) by creating job opportunities, access to finance and a broad network of stakeholders, thereby reducing the unemployed and impoverished population, and, indirectly contributes to wealth accumulation, economic growth and financial inclusion, particularly for developing and least developed countries. It also encourages innovation and entrepreneurial thinking and requires a certain level of financial literacy, inadvertently pushing stakeholders to increase their financial literacy and contributes indirectly toward SDG 4 (quality education).

Moreover, millenials, the "green generation", are said to be very sensitive towards the economic, social and environmental impacts of their actions. Accordingly, top sustainability purchasing drivers for participants aged 15-20 (Generation Z) of a global online study (Nielsen, s.d.) indicates that this group is willing to pay more if products: 1) come from a brand they trust (72\%), 2) are known for its health and wellness benefits $(70 \%), 3$ ) are made from fresh, natural and/or organic ingredients (69\%) and, 4) are from a company known for being environmentally friendly.

Furthermore, millennials are determined to "have a disproportionate desire for their investment decisions to reflect their social, political and environmental values". Further this group of people is also "more likely to accept a lower return or a higher risk related to an investment if it's in a company that has a positive impact on society and the environment"2.

\footnotetext{
${ }^{1}$ https://s3.amazonaws.com/aws-bsdc/BFT_BetterFinance_final_01192018.pdf

${ }^{2}$ https://medium.com/unleash-lab/un-sdgs-the-world-s-largest-intergenerational-wealth-transfer-f5a032b8542e
} 


\section{Literature Review}

A systematic review is a "specific methodology that locates existing studies, selects and evaluates contributions, analyses and synthesizes data, and reports the evidence in such a way that allows reasonably clear conclusions to be reached about what is and is not known" (Denyer and Tranfield, 2009: 671).

The databases for this review include the two most extensive databases (Chadegani et al., 2013): Scopus (www.scopus.com) and, WoS (www.clarivate.com/products/web-of-science). The search time frame starts at the inception of each database and ends on August 19, 2019. Search results (denoted as "all” in Table II) are limited to peer-reviewed articles. Overlapping and irrelevant articles are limited (denoted as "relevant" in Table II). The keyword/ keyword combinations shown in Table II have been used to determine the studies that have been published so far. The keywords have been selected as a result of a thorough review of media articles on the Internet and published research.

The research questions for the literature review are: (1) What dimensions of ECF success have been studied so far, and (2) is there any established literature on sustainability, blockchain technology and trust in the realm of ECF

An illustration of the systematic review employed in this study is presented in Table I below.

Table 1: Keywords/ Keyword combinations and search results

\begin{tabular}{llllll}
\hline & Wos and Scopus & Scopus & & WoS & \\
\hline Keyword & Total Relevant & Found & Relevant & Found & Relevant \\
\hline ECF & 237 & 222 & 186 & 158 & 112 \\
\hline + success & 42 & 46 & 37 & 45 & 38 \\
\hline + sustainability & 4 & 5 & 3 & 5 & 1 \\
\hline + trust & 3 & 5 & 3 & 6 & 0 \\
\hline + blockchain & 2 & 7 & 2 & 2 & 2 \\
\hline
\end{tabular}

The online Scopus database spans a period from 1960 to 2019. The search for the keyword "ECF" returned 222 articles, of which 113 are attributed to the disciplines of business, management and accounting, 108 to economics, econometrics and finance, 44 to computer science, 37 to social sciences, and the rest to decision sciences, engineering, mathematics, and arts and humanities. When the search was limited to relevant disciplines 186 remained. The majority of articles were published between 2016-2019.

The search for "ECF" in combination with "success" yielded 46 results, out of which 37 are relevant whereas the combination with "sustainability" yielded only 5 results, 3 of which are relevant, and the combination with "trust" yielded the same number of articles as with the previous keyword. As for the combination with "blockchain", 7 documents were found, out of which 2 are relevant.

The same keyword search procedure was applied to the WoS database, which covers a period from 1975 to 2019 . This initial search returned 158 results. While 112 of them are categorized as research articles, 33 are proceeding papers, 8 are reviews and the rest are editorial material and book reviews. The majority of the publications comes from the last three years. The top five countries publishing on this theme are: USA (38), Germany (20), China (19), England (18), France (14) and Italy (13). While 56 of the publications are related to the "business" field, 48 are attributed to the management discipline and 33 to the business finance literature. The remaining articles are classified as economics and law articles.

There is almost a 50\% overlap between those articles indexed by Scopus and WoS. The combination, after deducting recurring articles, is shown in Table I in the "total relevant" column. The highest number of relevant articles emerged from the search combined with success.

For instance, finance-based studies examine dual-class ECF models' success (Cumming et al., 2019), the relationship between medical crowdfunding and personal bankruptcy (Burtch and Chan, 2019), shareholder structure and venture performance (WalthoffBorm et al., 2018), the relationship between human capital of the entrepreneur (Piva and Rossi-Lamastra (2018), the gender of the founder (Malaga et al., 2018) or financial commitment (Löher et al., 2018).

There are also generalist papers focusing on campaign success attributing it, for instance, to cultural attributes (Josefy et al., 2017), including a sustainability orientation (Motylska-Kuzma, 2018; Vismara, 2019), and implementation of blockchain orientation (O'Dair and Owen, 2019). In his paper directly related to ECF, Vismara (2019), used a sample of 345 initial equity offerings in United Kingdom platforms Crowdcube and Seedrs in the period 2014-2015 and showed that although a sustainability orientation does not increase the chances of success or of engaging professional investors, it attracts a higher number of restricted investors. The restricted investors are interpreted to be considering community logic as opposed to professionals following market logic.

New music ventures might obtain alternative entrepreneurial finance through token sales or ICOs and a call out to policymakers is made to assist in developing this form of seed finance for the creative industries and beyond (O'Dair and Owen, 2019). Zhu and Zhou (2016) examined current problems in the practice of ECF in China and explored the practical applicability of blockchain 
technology. Accordingly, blockchain technology is found to 1) be a secure, efficient, low-cost solution for the registration of stocks and shares of a firm financed by crowdfunding, 2) simplify the transaction and transfer of crowdfunding equities, and thus facilitates their circulation, 3) enable peer to peer transactions between investors and entrepreneurs, and solves the problems of regulatory compliance and security of fund management, 4) have the potential to be used to develop a voting system for crowdfunders, which enables them to be involved in corporate governance and helps protect the rights and interests of small investors, and 5) help regulators know about market conditions, and support regulatory activities such as managing investors and fighting money laundering. Heieck et al. (2018) investigating the driving forces of ECF and the impact of blockchain technology, found that savings and financial benefits, facilitation of the financing process, satisfaction of intrinsic and social needs, outreach of projects and products, costs from equity funding, and financial provision have a positive effect, whereas risks from ECF, educational gap, investor protection, and monitoring problems and asymmetric information have a negative impact on equity funding. The authors concluded that ECF based on blockchain technology could be a feasible approach for financing startups if the counteracting effects are sufficiently mitigated. Angerer et al. (2017), analyzed success factors for the German crowd-investing market by conducting interviews. Key findings indicate that an attractive business model, an appropriate preparation in the pre-campaign period, ongoing activities during the campaign, and corresponding advertising activities can have a positive impact on the chances of an ECF campaign's success.

Next to economic factors, according to Molick (2014), behavioral factors such as social capital, which is essentially large amounts of capital funded by friends and family, and the type of a project, the creator's personality or control mechanisms (Thies et al., 2016, Wessel et al., 2017) have an influence on crowdfunding success. Davidson et al. (2013) contemplated that the lack of regulation could induce a negative effect on the investment decision since investors might feel uncomfortable in unregulated markets. Along the same lines, Ahlers et al. (2015) stated that the ECF market is substantially influenced by the legislative environment of its home country. Additionally, investors' inability to meet entrepreneurs in person and conduct detailed due diligence (Beckwith, 2016) may increase the risks associated with investing on ECF platforms or even make them a target for fraud (Argawal, Catalini, \& Goldfarb, 2013).

One unique study that focuses on how campaign and firm characteristics are associated with follow-up funding and firm failure (Hornuff et. al, 2018) provides initial empirical evidence from Germany and the UK. Among the characteristics the authors found to have positive (negative) effect on follow-up funding are the number of senior managers, registered trademarks, subsequent successful ECF campaigns, crowd exits, and the amount of the funding target (firm age, the average age of the management team, and excessive funding during the ECF campaign), however a sustainability-orientation was not measured. Calic and Mosakowski (2016) established that: 1) a sustainability orientation positively affects funding success of crowdfunding projects, and 2) this relationship is partially mediated by project creativity and third party endorsements. However, the study is limited to particular types of projects, a rewardsbased crowdfunding platform and only one-dimensional aspects of environmental and social sustainability. However, the authors argue that "early research suggests that reward-based and ECF may be complementary, serving different needs. Lukkarinen et al. (2016) in their analysis of Invesdor, a leading ECF platform in Northern Europe determined a 30\% success rate, which they liken to the success rates of other crowdfunding platforms. They suggest that the investment decision criteria traditionally used by VCs or business angels are not of prime importance for success in ECF. The authors also argued that success is related to pre-selected crowdfunding campaign characteristics and the utilization of private and public networks and suggested that to better understand the dynamics of crowdfunding and to improve campaign success rates, knowledge of the factors contributing to success in crowdfunding is required. What makes this paper particularly interesting is their argument that emotional and social criteria may be more important to equity crowdfunders than financials. The observation leading them to this speculation is that the contracts prevalent in ECF are typically not very attractive from the perspective of financial investors, with long-term durations and without dividends or voting rights.

Ramos (2014) interviewed managers of various types of crowdfunding platforms like equity but also donation, lending and rewardsbased ones, determines the success factors to be: 1) Improving the quality of the projects and campaigns, 2) encouraging growing user participation, 3) providing personalized assistance, 4) reducing financing costs, and, 5) having a clear understanding of their users' needs.

Aspara and Tikkanen (2011) established that the more positive an individual's attitude towards the company was, the stronger was his extra investment motivation.

As a result, the emerging themes from the systematic literature review are presented in Table 2 below: 
Table 2: Emerging themes in relation to ECF and Success

\begin{tabular}{|c|c|c|}
\hline Theme & Findings & Author(s) \\
\hline \multirow{6}{*}{$\begin{array}{l}\text { Investor's attention to signals / venture } \\
\text { and campaign characteristics }\end{array}$} & General discussions propel investment, while certain topics decrease funding success. & Kleinert and Volkmann (2019) \\
\hline & Internal certification mechanisms like the availability of human capital can help achieve funding goals. & Ahlers et al. (2015) \\
\hline & Human capital, investors' experience, and social capital are credible signals for start-up investment in ECF. & An (2019) \\
\hline & $\begin{array}{l}\text { ECF investors are rational, interpreting signals derived from firm attributes and financial statements to } \\
\text { minimize risk and maximize returns. The firm's and entrepreneur's social networks also have a strong } \\
\text { influence on investment decisions. }\end{array}$ & Nitani et al. (2019) \\
\hline & $\begin{array}{l}\text { Campaign characteristics, which can be pre-determined beforehand: the funding target, the minimum } \\
\text { investment, campaign duration, and the provision of financials. }\end{array}$ & Lukkarinen et al. (2016) \\
\hline & $\begin{array}{l}\text { Campaign characteristics like target amount, percentage equity and, company characteristics like previous } \\
\text { backing, accelerator attendance, intellectual property rights protection, and company } \\
\text { age, and information about the founders and management team. }\end{array}$ & Ralcheva and Roosenboom (2019) \\
\hline \multirow{2}{*}{ Voting rights } & $\begin{array}{l}\text { A higher separation between ownership and control rights lowers the probability of success of the offering, } \\
\text { the likelihood of attracting professional investors, as well as the long-run prospects. }\end{array}$ & Cumming et al. (2019) \\
\hline & $\begin{array}{l}\text { The delivery of individual voting rights is associated with lower chances of success of the platforms, whereas } \\
\text { the delivery of pooled voting rights is not significant. }\end{array}$ & Rossi et al. (2019). \\
\hline \multirow{2}{*}{ Existence of non-financial benefits } & $\begin{array}{l}\text { Inward benefits are aimed at the entrepreneurs and, when harnessed, can become resources that advance future } \\
\text { success. }\end{array}$ & Wald et al. (2019) \\
\hline & $\begin{array}{l}\text { A sustainability orientation does not increase the chances of success or of engaging professional investors but } \\
\text { it attracts a higher number of restricted investors. }\end{array}$ & Vismara (2019) \\
\hline $\begin{array}{l}\text { Effect of risks and investor's attention to } \\
\text { signals / venture and campaign } \\
\text { characteristics }\end{array}$ & $\begin{array}{l}\text { ECF investors consider market, execution and agency risks and they are responsive to the venture's ability to } \\
\text { attract traditional venture capital funding prior to ECF. }\end{array}$ & Mamonov and Malaga (2019) \\
\hline
\end{tabular}




\section{Theoretical Background}

The concept of crowdfunding by nature, as explained throughout the text, is engrained in uncertainty surrounding the venture, the platform, the process, and the entrepreneurs.

The literature on ECF has relied on the theory of signaling (Spence, 1973), to determine which ECF pitch qualities are most likely to influence the investors' decision to dedicate funds to a campaign. Using credible signals in lieu of unobservable characteristics about a venture or campaign, entrepreneurs can convey positive information about their venture (Ralcheva and Roosenboon, 2019).

On the other hand, legitimacy theory posits that organizations are expected to act in a socially acceptable manner so as to access resources, gain approval of their goals and place in the society, and guarantee continued existence (Guthrie \& Parker, 1989). Thus, legitimacy is closely related to trust. In adopting a legitimacy theory perspective, a company would voluntarily report on activities if management perceived that those activities were expected by the communities in which it operates (Deegan 2002).

Additionally, according to stakeholder theory, the corporation's continued existence requires the support of the stakeholders and their approval must be sought and the activities of the corporation adjusted to gain that approval. The more powerful the stakeholders, the more the company must adapt. Social disclosure is thus seen as part of the dialogue between the company and its stakeholders (Gray, Kouhy \& Lavers 1995).

Descriptive stakeholder research seeks to describe the corporation in relation to its environment and views it as a constellation of cooperative and competitive interests possessing intrinsic value (Donaldson \& Preston, 1995).

Legitimacy and stakeholder approval can in most cases be achieved by pursuing social, environmental and economic goals in line with the unanimously accepted United Nations Sustainable Development Goals (SDGs, s.d.) to signal trustworthiness and reliability of the venture. At any rate, stakeholder pressure soon may arise demanding the reporting of sustainability practices of any kind of organization. Security in online transactions, another issue may push away potential investors, can be signaled through incorporating the safety of a blockchain technology infrastructure.

\section{Discussion}

The purpose of this exploratory study has been to provide insight into the success factors of ECF campaigns and, in particular, explore the role of trust. In specific, the research questions for this study are: (1) What dimensions of ECF success have been studied so far? and (2) is there any established literature on blockchain technology and ECF.

The literature review has revealed that the role of trust is an emerging theme, and sustainability and BT in relation to trust, to the best of the author's knowledge, is not yet focused upon in crowdfunding research.

While, as shown in the literature review, empirical studies on the relationship between ECF and sustainability elements are very limited, the relationship between social and financial returns for established firms has already been studied to a great extent since the last two decades. Evidently, social returns are in most cases related to financial returns. As such, long-term financial benefits may exist when corporate social responsibility is improved (Ruf et al., 2001), poor environmental performance significantly affects the intangible asset value of firms (Konar and Cohen, 2001), and, corporate social and environmental appears to be more highly correlated with accounting-based measures of corporate financial performance than with market-based indicators (Orlitsky et al., 2003).

The theoretical framework underscores that stakeholders value legitimate ventures and a good way to legitimize business activities is by showing proof of impact to society, the economy, and the environment. Consequently, adopting SDGs and integrating BT, serve as tools for signaling transparency, legitimacy, impact-orientation, and attention to innovation.

This paper proposes sustainability as a trust "signal" that will foster more transparency and may retain existent patient capital while attracting yet another segment: the socially mindful investors seeking impact investment opportunities. This can be achieved through adopting social listing requirements on part of the ECF platform or by investors demanding (stakeholder pressure), and the publication of sustainability elements or stand-alone or integrated sustainability reports from the campaign owner (push and pull factors).

Embedding sustainability sentiment into digital pitches will serve towards "getting one's point across" in a legitimate (as discussed in the theoretical background section under legitimacy theory) and accommodating style, and thereby attract a greater investor base while sustainability reporting, as a risk management tool, will offer higher transparency and retain existing investors while serving as a powerful outreach and advocacy mechanism.

The second potential trust signal, BT, reaches far beyond cryptocurrencies. BT is a way of decentralizing and democratizing access to finance.

Based on media research and the previously described systematic literature review, BT technology will be complementary to ECF as a democratizing mechanism offering multiple funding options for SMEs and sustainability elements legitimizing the existence of such ventures through promoting the five P's of sustainable development: people, planet, prosperity, peace and partnership (Sachs, 2015). 


\section{Conclusions}

Sustainability should be a sine qua non for any type of venture, but studies show that, to be successful, sustainability in itself is not a unique selling point (Bocken, 2015). While it certainly is a catalyst towards legitimation, more is needed to enhance and maximize both, total and individual shareholder value. To that end, each shareholder, or potential stakeholder of the venture must be identified. Future research may study the different motivational factors for each stakeholder in relation to trust, sustainability and BT.

Moreover, stakeholders should be given clear cues and financial-sustainability education on the risks of ECF investments and about how their contributions to ventures embracing sustainability issues, matter to the universal good of our societies. Impact measurement and sustainability reporting in that realm will prove to be a powerful tool.

Consequently, the main contribution of this study is to draw attention to new trust-enhancing tools and allude to the necessity to address each of these questions in separate theoretical, and, depending on the availability of data, empirical studies since a comprehensive understanding of the success drivers, and the trust determinant in specific, is vital for the advancement of ECF.

To this end, ECF platforms, may also serve as social community outreach projects, which may increase their popularity and legitimacy. They may act as ambassadors of education, create a contagion effect and entice other ventures to do the same. That way, collaboration and subsidies by local government and international sustainability initiatives, such as organizations such as the United Nations Environment Programme Finance Initiative (UNEP FI, s.d.), the United Nations Global Compact (s.d.), and the Principles for Responsible Investment (PRI, s.d.), may potentially be solicited.

\section{References}

Acorn (s.d.) 4 Crowdfunding Trends to Keep Your Eye on for 2018. Accessed at: https://medium.com/@ coinrecaps/4-crowdfundingtrends-to-keep-your-eye-on-for-2018-837358188e45. Date accessed: 01.11.2019.

Aghaei Chadegani, A., Salehi, H., Yunus, M., Farhadi, H., Fooladi, M., Farhadi, M., \& Ale Ebrahim, N. (2013). A comparison between two main academic literature collections: Web of Science and Scopus databases. Asian Social Science, 9(5), 18-26.

Anderson, E., \& Weitz, B. (1989). Determinants of continuity in conventional industrial channel dyads. Marketing Science, 8(4), 310-323.

Aspara, J., \& Tikkanen, H. (2011). Corporate marketing in the stock market: The impact of company identification on individuals' investment behaviour. European Journal of Marketing, 45(9/10), 1446-1469.

Bocken, N. M. P. (2015). Sustainable venture capital-catalyst for sustainable start-up success?. Journal of Cleaner Production, 108, 647-658.

Burtch, G., \& Chan, J. (2018). Investigating the relationship between medical crowdfunding and personal bankruptcy in the United States: Evidence of a digital divide. MIS Quarterly (Forthcoming).

Calic, G., \& Mosakowski, E. (2016). Kicking off social entrepreneurship: how a sustainability orientation influences crowdfunding success. Journal of Management Studies, 53(5), 738-767.

Campbell, D., Craven, B., \& Shrives, P. (2003). Voluntary social reporting in three FTSE sectors: a comment on perception and legitimacy. Accounting, Auditing \& Accountability Journal, 16(4), 558-581.

Cumming, D., Meoli, M., \& Vismara, S. (2019). Investors' choices between cash and voting rights: Evidence from dual-class equity crowdfunding. Research Policy, 48(8), 103740.

Denyer, D., \& Tranfield, D. (2009). Producing a systematic review. The Sage Handbook of Organizational Research Methods, 671689.

Dobelli, R. (2013). The art of thinking clearly: better thinking, better decisions. Hachette UK.

Donaldson, T., \& Preston, L. E. (1995). The stakeholder theory of the corporation: Concepts, evidence, and implications. Academy of Management Review, 20(1), 65-91.

Duffner, S., Schmid, M. M., \& Zimmermann, H. (2009). Trust and success in venture capital financing-an empirical analysis with German survey data. Kyklos, 62(1), 15-43.

EBF (s.d.). Accessed at: https://www.europeanblockchainfoundation.org. Date accessed: 19.07.2019.

Forbes (2018). Accessed at: https://www.forbes.com/sites/lawrencewintermeyer/2018/03/02/seedrs-the-most-active-uk-funder-ofprivate-companies/. Date accessed: 19.08.2019.

Forbes, H., \& Schaefer, D. (2017). Guidelines for Successful Crowdfunding. Procedia CIRP, 60, 398-403.

Freedman, D. M., \& Nutting, M. R. (2015). A brief history of CROWDFUNDING including rewards, donation, debt, and equity platforms in the USA. Retrieved, 30, 2016.

Gray, R., Kouhy, R., \& Lavers, S. (1995). Corporate social and environmental reporting: a review of the literature and a longitudinal study of UK disclosure. Accounting, Auditing \& Accountability Journal, 8(2), 47-77.

GRI (s.d.) Accessed at: https://www.globalreporting.org/standards/. Date accessed: 19.08.2019.

Guthrie, J., \& Parker, L. D. (1989). Corporate social reporting: a rebuttal of legitimacy theory. Accounting and Business research, 19(76), 343-352.

Heieck, F., Ermakova, T., Fabian, B., and Lessmann, S. (2018) ECF Based on the Blockchain? - A Delphi Study. Accessed at https://ssrn.com/abstract=3198083 or http://dx.doi.org/10.2139/ssrn.3198083. Date accessed: 01.03.2019 
Hornuf, L. and Schmitt, M. (2016) : Success and Failure in ECF, CESifo DICE Report, ISSN 1613-6373, ifo Institut - Leibniz-Institut für Wirtschaftsforschung an der Universität München, München, Vol. 14, Iss. 2, pp. 16-22.

Hornuf, L., Schmitt, M., and Stenzhorn, E. (2018). ECF in Germany and the UK: Follow-Up Funding and Firm Failure. Max Planck Institute for Innovation \& Competition Research Paper No. 17-09; CESifo Working Paper Series No. 6642.

IIRC (s.d.). Accessed at: http://integratedreporting.org. Date accessed: 19.08.2019.

Infodev (s.d.). Accessed at: http://www.infodev.org/infodev-files/wb_crowdfundingreport-v12.pdf. Date accessed: 19.08.2019.

Islam, M.A. (2015), Social Compliance Accounting, CSR, Sustainability, Ethics \& Governance, Springer International Publishing Switzerland DOI 10.1007/978-3-319-09997-2_2.

JBS (s.d.). Accessed at: https://www.jbs.cam.ac.uk/fileadmin/user_upload/research/centres/alternative-finance/downloads/2017-06americas-alternative-finance-industry-report.pdf. Date accessed: 19.08.2019.

Johansson, I. L., \& Baldvinsdottir, G. (2003). Accounting for trust: some empirical evidence. Management Accounting Research, 14(3), 219-234.

Josefy, M., Dean, T. J., Albert, L. S., \& Fitza, M. A. (2017). The role of community in crowdfunding success: Evidence on cultural attributes in funding campaigns to "Save the local theater". Entrepreneurship Theory and Practice, 41(2), 161-182.

Konar, S., \& Cohen, M. A. (2001). Does the market value environmental performance?. Review of Economics and Statistics, 83(2), 281-289.

Löher, J., Schneck, S., \& Werner, A. (2018). A research note on entrepreneurs' financial commitment and crowdfunding success. Venture Capital, 20(3), 309-322.

Lukkarinen, A., Teich, J. E., Wallenius, H., \& Wallenius, J. (2016). Success drivers of online ECF campaigns. Decision Support Systems, 87, 26-38.

Malaga, R., Mamonov, S., \& Rosenblum, J. (2018). Gender difference in ECF: an exploratory analysis. International Journal of Gender and Entrepreneurship, 10(4), 332-343.

Medium (s.d.). Accessed at: https://medium.com/\%C3\%B5petfoundation/world-blockchain-organization-united-nationsblockchain-foundation-endorses-opet-foundation-dc97d8c26ce8. Date accessed: 19.08.2019.

Morgan, R. M., \& Hunt, S. D. (1994). The commitment-trust theory of relationship marketing. Journal of Marketing, 58(3), $20-38$.

Motylska-Kuzma, A. (2018). Crowdfunding and Sustainable Development. Sustainability, 10(12), 4650.

Multi-UN. (s.d.). Accessed at https://un-blockchain.org. Date accessed: 26.09.2019.

Neu, D., Warsame, H., \& Pedwell, K. (1998). Managing public impressions: Environmental disclosures in annual reportsa. Accounting, Organizations and Society, 23(3), 265-282.

Nielsen (s.d.). Accessed at: https://www.nielsen.com/eu/en/insights/reports/2015/the-sustainability-imperative.html. Date accessed: 19.08.2019.

O'Dair, M., \& Owen, R. (2019). Financing new creative enterprise through blockchain technology: Opportunities and policy implications. Strategic Change, 28(1), 9-17.

O'Dwyer, B. (2005). Stakeholder democracy: challenges and contributions from social accounting. Business Ethics: A European Review, 14(1), 28-41.

Orlitzky, M., Schmidt, F. L., \& Rynes, S. L. (2003). Corporate social and financial performance: A meta-analysis. Organization studies, 24(3), 403-441.

Piva, E., \& Rossi-Lamastra, C. (2018). Human capital signals and entrepreneurs' success in ECF. Small Business Economics, 51(3), 667-686.

PRI (s.d.). Principles for Responsible Investment.Accessed at: https://www.unpri.org/. Date accessed: 01.04.2019.

Primavera De Filippi. Blockchain-based Crowdfunding: what impact on artistic production and art consumption?. version anglaise de Crowdfunding baseado em blockchain: qual seu impacto sobre a produção artísti.. 2016.

PRNewswire (s.d.). Accessed at https://www.prnewswire.com/news-releases/the-global-blockchain-market-size-is-expected-togrow-from-usd-1-2-billion-in-2018-to-usd-23-3-billion-by-2023--at-a-compound-annual-growth-rate-cagr-of-80-2300762798.html. Date accessed: 10.09.2019

Ralcheva, A., \& Roosenboom, P. (2019). Forecasting success in equity crowdfunding. Small Business Economics, 1-18.

Ramos, J. (2014). Crowdfunding and the role of managers in ensuring the sustainability of Crowdfunding platforms. JRC Scientific and Policy Reports, 85752.

Rossi, A., Vismara, S., \& Meoli, M. (2019). Voting rights delivery in investment-based crowdfunding: a cross-platform analysis. Journal of Industrial and Business Economics, 46(2), 251-281.

Ruf, B. M., Muralidhar, K., Brown, R. M., Janney, J. J., \& Paul, K. (2001). An empirical investigation of the relationship between change in corporate social performance and financial performance: A stakeholder theory perspective. Journal of Business Ethics, 32(2), 143-156.

Sachs, J. D. (2015). The age of sustainable development. Columbia University Press.

Schwienbacher, A. (2019). ECF: anything to celebrate? Venture Capital, 21(1), 65-74.

Seedrs (s.d.). Accessed at: http://www.seedrs.com. Date accessed: 01.10.2019.

Seeds (s.d.). Accessed at: https://www.seedrs.com/learn/blog/beauhurst-confirms-seedrs-as-the-uks-top-funder. Date accessed: 19.08.2019

Solomon, R. C., \& Flores, F. (2003). Building trust: In business, politics, relationships, and life. Oxford University Press. 
Son-Turan, S. (2015). Financial Innovation-Crowdfunding: Friend or Foe? Procedia-Social and Behavioral Sciences, 195, $353-362$.

Son-Turan, S. (2017). Emerging Trends in the Post-Regulatory Environment: The Importance of Instilling Trust. In Risk Management, Strategic Thinking and Leadership in the Financial Services Industry (pp. 345-354). Springer, Cham.

Spence, M. (1978). Job market signaling. In Uncertainty in economics (pp. 281-306). Academic Press.

Statista (s.d.). Accessed at: https://www.statista.com/outlook/335/100/crowdfunding/worldwide. Date accessed: 19.08.2019.

Tapscott, D., \& Tapscott, A. (2016). Blockchain revolution: how the technology behind bitcoin is changing money, business, and the world. Penguin.

Thies, F., Wessel, M., \& Benlian, A. (2016). Effects of social interaction dynamics on platforms. Journal of Management Information Systems, 33(3), 843-873.

UN Blockchain (s.d.) Accessed at: https://un-blockchain.org/. Date accessed: 19.08.2019.

UNDP (s.d.). Accessed at: http://www.undp.org/content/dam/sdfinance/doc/Crowdfunding\%20_\%20UNDP.pdf. Date accessed: 19.08.2019.

UNEP FI (s.d.) United Nations Environment Programme Finance Initiative. Accessed at: https://www.unepfi.org/. Date accessed: 01.11.2019.

United Nations Global Compact (s.d.). Accessed at: https://www.unglobalcompact.org. Date accessed: 01.11.2019.

UNWBO (s.d.). Accessed at: http://www.unwbo.org/\#whoweare. Date accessed: 20.07.2019.

Van der Laan, S. (2009). The role of theory in explaining motivation for corporate social disclosures: Voluntary disclosures vs solicited disclosures. Australasian Accounting Business \& Finance Journal, 3(4), 15A.

Venturebeat (s.d.). Accessed at: https://venturebeat.com/2018/06/09/todays-best-crowdfunding-platforms-by-the-numbers/. Date accessed: 19.08 .2019

Vismara, S. (2019). Sustainability in Equity Crowdfunding. Technological Forecasting and Social Change, 141, 98-106.

Vulkan, N., Åstebro, T., \& Sierra, M. F. (2016). Equity Crowdfunding: A new phenomena. Journal of Business Venturing Insights, 5 , $37-49$.

Wald, A., Holmesland, M., \& Efrat, K. (2019). It Is Not All About Money: Obtaining Additional Benefits Through Equity Crowdfunding. The Journal of Entrepreneurship, 28(2), 270-294.

Walthoff-Borm, X., Vanacker, T. R., \& Collewaert, V. (2018). ECF, shareholder structures, and firm performance. Corporate Governance: An International Review, 26(5), 314-330.

Yan, Z., \& Cofta, P. (2004, August). A mechanism for trust sustainability among trusted computing platforms. In International Conference on Trust, Privacy and Security in Digital Business (pp. 11-19). Springer, Berlin, Heidelberg.

Zhu, H., \& Zhou, Z. Z. (2016). Analysis and outlook of applications of blockchain technology to Equity Crowdfunding in China. Financial Innovation, 2(1), 29.

Publisher's Note: SSBFNET stays neutral with regard to jurisdictional claims in published maps and institutional affiliations.

\section{(c) (1)}

(C) 2021 by the authors. Licensee SSBFNET, Istanbul, Turkey. This article is an open access article distributed under the terms and conditions of the Creative Commons Attribution (CC BY) license (http://creativecommons.org/licenses/by/4.0/).

International Journal of Research in Business and Social Science (2147-4478) by SSBFNET is licensed under a Creative Commons Attribution 4.0 International License. 